\title{
Network Position, Technological Distance and Firm's Cooperation Innovation
}

\author{
Jiayu Chi', Ling Sun ${ }^{2}$ \\ ${ }^{1}$ School of Business, Sun Yat-sen University, Guangzhou, China \\ ${ }^{2}$ Lingnan College, Sun Yat-sen University, Guangzhou, China \\ Email: chijiayu@mail.sysu.edu.cn
}

How to cite this paper: Chi, J.Y. and Sun, L. (2018) Network Position, Technological Distance and Firm's Cooperation Innovation. American Journal of Industrial and Business Management, 8, 2180-2190. https://doi.org/10.4236/ajibm.2018.811145

Received: October 29, 2018

Accepted: November 19, 2018

Published: November 22, 2018

Copyright ( 92018 by authors and Scientific Research Publishing Inc. This work is licensed under the Creative Commons Attribution International License (CC BY 4.0).

http://creativecommons.org/licenses/by/4.0/

(c) (i) Open Access

\begin{abstract}
This paper studied the joint effects of network position and technological distance on firm's cooperation innovation based on the data of firm's patent cooperation from 2003-2013 in the electronic information, electric power and equipment manufacturing industry. Results show that both network centrality and structure holes have a significant positive impact on the firm's cooperation innovation output; technological distance and cooperative innovation performance have an inverted u-shaped relationship; the interaction of network centrality and technological distance negatively regulates the cooperative innovation performance; the interaction of technological distance and structure holes can promote cooperative innovation performance.
\end{abstract}

\section{Keywords}

Network Position, Technological Distance, Cooperation Innovation

\section{Introduction}

With the rapid development of science and technology and the increasing competition of technology, the inter-organization innovation cooperation network is playing a more and more important role in the process of firm's technological innovation. Cooperative innovation can help firm quickly master cutting-edge technology, reduce the cost of firm's R\&D and control innovation risk, so as to effectively enhance the innovation output of firms. In the international trend of cooperative technology innovation becoming the main form of firm's technological innovation activities, firms are faced with strategic opportunities to join the technology innovation network, acquire new knowledge, and enhance the technological innovation ability of firms [1].

The network position characteristics will affect the technological innovation 
performance of the firms in the cooperative technology innovation network, and the firms occupying the superior network position can easily obtain valuable information and resources in the network. In addition to the network position, the technology distance between firms and their partners (i.e., the difference of technology space between the two firms) will also affect the technology spillover mechanism of innovation networks, and then affect the performance of cooperative innovation. Scholars have conducted some independent research on the impact of network position and technological distance on enterprise innovation. But the research on how the network position and technology distance work together on the firm's innovation output is still limited.

Based on the analysis of cooperative patent data of 189 firms in electronic information, power and equipment manufacturing industry in China during the past 2003-2013 years, this paper discusses the impact of network position and technology distance and the interaction between them on the performance of cooperative technology innovation. This research is great significance for firms to choose technology innovation partners and build technological innovation network.

The reminder of the paper is organized as follows. In the next section, we develop the research model and propose hypotheses. Then, we report data collection, variable measurement, and the results of the data analysis. Finally, we discuss the major findings and their implications for research and practice.

\section{Theory and Hypothesis}

\subsection{Network Structure and Firm's Cooperative Innovation Output}

1) Network centrality and firm's cooperation innovation output

Because of the rich information channels and information sources, firms with high centrality can integrate this information to form unique and novel knowledge [2]. From the perspective of organizational learning theory, new information and access to more business contact, more able to enhance their ability to identify and study, so that firms can be more easily to obtain accurate and valuable information, and will obtain external information and existing knowledge integration, assimilation and absorption, the formation of new knowledge, further to improve the performance of firm's innovation [3].

Therefore, the following hypotheses are proposed:

Hypothesis 1a: the network centrality of firms has a positive impact on their collaborative innovation output.

2) Structural holes and firms' cooperative innovation output

According to the theory of structural holes, the concepts and behaviors between groups are heterogeneous compared to the ideas and behaviors within the group [4]. Thus, individuals across multiple groups can acquire the ideas and behaviors of another group more quickly. The firm's structure hole in the network is equivalent to an intermediary, plays a very important intermediary role, will be responsible for each other without link connected firms, strategic posi- 
tion in a multi group information gathering, is the critical path of network information flow, so that the firm can control all kinds of key information and the key resources, and may have some degree of control and information resources in network and the flow way, enjoy the benefits of control structure caused by the hole [5].

Accordingly, this paper proposes the following research hypotheses:

Hypothesis 1b: the position of the structural holes occupied by the firm has a positive impact on its collaborative innovation output.

\subsection{Technology Distance and Firm's Cooperation Innovation Output}

Gilsing et al. (2008) argued that technology distance has a negative effect on absorptive capacity of firms in cooperative innovation networks, but has positive effects on firm's information value [6]. Therefore, when the distance is very small, with the distance gradually increased, gradually improve the cooperative innovation performance, when the distance exceeds a certain point, with the increase of distance, cooperation and innovation network in firms cannot effectively absorb knowledge, will lead to a gradual decline in the performance of technological innovation. Mutual understanding is the foundation of establishing the relationship of cooperative technological innovation, but firms may not get heterogeneous information because they are too familiar with and understand each other, which is not conducive to technological innovation. As a result, companies seek a partner who is not very familiar with them to learn new knowledge, but it is too difficult to build a cooperative relationship with each other through too much technical distance.

Accordingly, this paper proposes the following assumptions.

Hypothesis 2: there is an inverted $U$ type relationship between technological distance and technological innovation performance among firms.

\subsection{Interaction between Network Structure and Technology Distance}

Occupying the superior network position is advantageous for the firm to obtain the more valuable information, more convenient and quick searches the network the resources, provides the condition for the firm's technical innovation activity. Technology distance is the precondition of knowledge spillover effect among firms, so the interaction between network position and technology distance will affect the cooperative innovation performance of firms. Firms with low network centrality are at the edge of the network. There is less opportunity for them to establish direct cooperation relationship with other firms, and obtain new information from outside. Therefore they can choose high technology distance partners to enrich their technical knowledge. Thence the network center and technology distance has a substitution effect. Firm's structure holes play the role of a bridge and an important intermediary role in the dense network, if we can choose the high technology distance partners, will further promote the flow of 
technical knowledge in the heterogeneous network, enjoy higher gain new knowledge and new knowledge to control income, so the firm's structure holes and technology the distance have complementary effect.

Accordingly, this paper proposes the following research hypotheses:

Hypothesis 3a: the interaction between technology distance and network centrality has a negative impact on the cooperative technological innovation performance of firms.

Hypothesis 3b: the interaction between technology distance and structural holes has a positive impact on the cooperative technological innovation performance of firms.

Based on the theoretical research of the above conceptual model, this paper puts forward the relevant research hypotheses, and finally obtains the research model and related assumptions as shown in Figure 1.

\section{Research Design and Research Methods}

\subsection{Data Collection}

The data of this study include the main sources: 1) the patent retrieval platform of the State Intellectual Property Office, the platform covers the detailed information of the eight key industries of patent application and authorization; 2) the web sites of provinces and cities' Industrial and Commercial Bureau, these websites can some obtain basic information such as the registered capital, registration time, and type of business of each company.

This study uses snowball sampling method to collect the sample data, the first 100 companies in 2013 Chinese electronic information industry hundred firms on the list as the sample as the core of the firm's cooperation innovation network; and to identify these firms based on cooperation for invention patents of the firm; finally through the analysis of patent data of all samples of firm's cooperation the identification of technical cooperation between firms. Three times through the snowball method and implementation of the screening criteria, the cooperation between firm's technology innovation network consists of 189 companies, mainly from electric and electronic information, equipment manufacturing

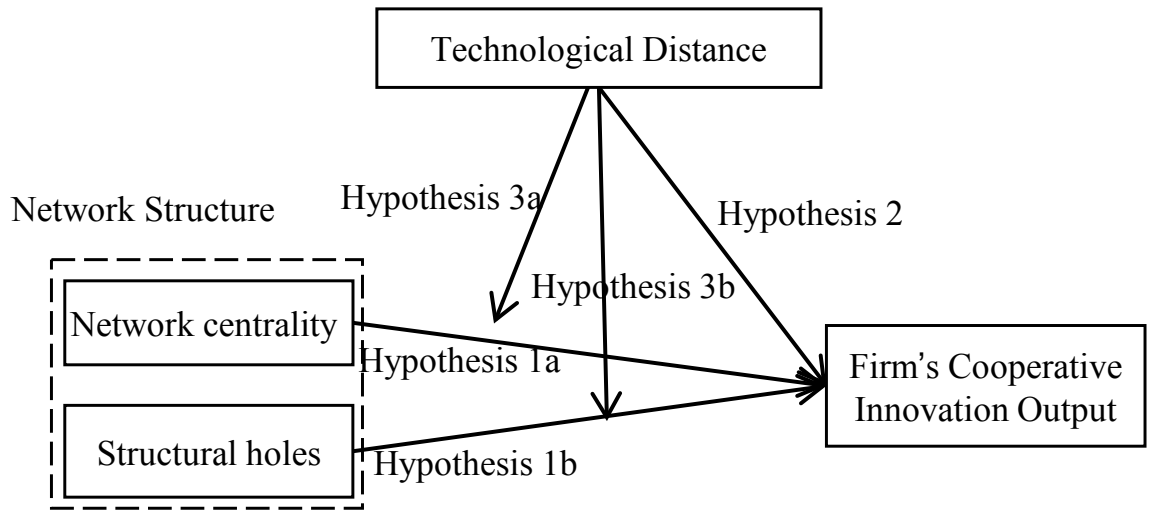

Figure 1. Research models and related hypothesis. 
and other three industries, these firms cooperation for 294 patents in 2003-2013.

\subsection{Measurement of Dependent Variable}

The dependent variable of the study is the firm's cooperative innovation output. The total number of cooperative patents granted by a firm and all other joint patent companies during the 2003-2013 years is taken as the measurement index of the firm's cooperative innovation output.

\subsection{Measurement of Independent Variable}

1) Network centrality: Degree centrality is the most appropriate index to measure the external information and knowledge ability of individual actors in the measurement network. In this study, degree centrality is used as a measure of centrality of firm's networks [7].

2) Structural holes: The limit degree is a widely used index to measure structural holes, which represents the degree of scarcity of structural holes. In this study, the difference between the 1 and the limit is used as the measurement value of the number of structural holes [8].

3) Technical distance: Jaffe propose the concept of technical distance [9]. This study uses the correlation coefficient method of firm's patent portfolio proposed by Bar et al. to measure the technical distance between firms, which can be calculated by the following formula [10].

$$
T D_{i j}=\frac{\sum_{k} p_{i k} p_{j k}}{\sqrt{\left(\sum_{k} p_{i k}^{2}\right)\left(\sum_{k} p_{j k}^{2}\right)}}
$$

Among them, $T D_{i j}$ represents the technical distance between firm $I$ and firm $J$, and $P_{i k}$ and $P_{J K}$ represent the number of invention patents under class $K$ patents of firm $I$ and firm $J$ in a certain period of time. If the value is closer to 1 , the smaller the technical distance between the two firms, the closer the value is to 0 , the greater the technical distance between the two firms. In this paper, $1-T D_{i j}$ is used as the measurement value of technical distance, and the average technical distance between the firm and all partners is taken as the technical distance measurement index of the node firm.

\subsection{Measurement of Control Variable}

The control variables included firm size, firm age and firm type. In this study, the registered capital represents the size of the firm and the age of the firm is the number of years experienced by the firm from the registration date to the date of the data collection. In this study, the types of firms are divided into state owned or state holding firms, wholly foreign-owned firms, Sino foreign joint ventures, private firms and others, and 4 dummy variables are set up for the five types of firms. 


\section{Results and Discussion of Empirical Analysis}

Using UCINET6.0 social network analysis software, this paper constructs the cooperative innovation network among firms, calculates the parameter value of network position, and uses Stata 11 software to test the above hypothesis by using the method of hierarchical regression.

Table 1 shows the mean, standard deviation and correlation coefficient of all variables. As shown in Table 1 , network centrality, structural holes and cooperative innovation output are significantly positively correlated with $\mathrm{p}<0.1 \%$ level.

Table 2 lists the regression analysis results of the network structure and technology distance on the relationship between firm's cooperation and innovation. The data results show that model 1 to model 5 are statistically significant ( $\mathrm{p}<$ 0.001). The model 1 goodness of fit statistic Pseudo R2, which only considers the control variables, is 0.0551 , which shows that the explanatory variables of the control variables are relatively low in the cooperative technology innovation performance.

In model 2, the network center of cooperative technological innovation performance of the regression coefficient is 0.303 and significant at the $1 \%$ level, indicating that the network centrality has significant positive effect on the performance of technical innovation cooperation, which is in the center position of network cooperative innovation performance of firms is higher, to verify the hypothesis H1a.

From model 3 the regression coefficient of structure holes on the performance of technical innovation cooperation is 1.671 and significant at the $1 \%$ level, indicating the structure holes has significant positive effect on the performance of technical innovation cooperation, namely the firm more rich in structural holes occupy the network position, firm's cooperation innovation performance is higher, by verifying the hypothesis $\mathrm{H} 1 \mathrm{~b}$.

From the model 4, 0.603 and significant at the $1 \%$ level is the regression coefficient of technology distance, -0.872 and significant at the $1 \%$ level is the square of the distance of the regression coefficient, indicating the existence of significant inverted $U$ relation performance of cooperative technology innovation and firm's technology distance between firms, technology distance is too large or too small is not conducive to cooperation in technological innovation activities of firms, there is an optimal value, through the verification of hypothesis 2 .

Table 1. Descriptive statistics and correlation coefficients.

\begin{tabular}{ccccccc}
\hline & $\begin{array}{c}\text { Mean } \\
\text { value }\end{array}$ & $\begin{array}{c}\text { standard } \\
\text { deviation }\end{array}$ & $\begin{array}{c}\text { Cooperative } \\
\text { innovation }\end{array}$ & $\begin{array}{c}\text { Network } \\
\text { centrality }\end{array}$ & $\begin{array}{c}\text { Structural } \\
\text { holes }\end{array}$ & $\begin{array}{c}\text { Technical } \\
\text { distance }\end{array}$ \\
\hline $\begin{array}{c}\text { Cooperative } \\
\text { Innovation } \\
\text { Network }\end{array}$ & 4.05 & 8.24 & 1 & 1 & & \\
$\begin{array}{c}\text { Centrality } \\
\text { Structural Holes }\end{array}$ & 0.18 & 0.41 & $0.694^{* * *}$ & $0.459^{* * *}$ & 0.589 & 1 \\
$\begin{array}{c}\text { Technical } \\
\text { Distance }\end{array}$ & 0.71 & 1.24 & 0.133 & 0.106 & 0.178 & 1 \\
\hline
\end{tabular}

Note: ${ }^{*}{ }^{* *}, * *$ means $\mathrm{p}<0.1, \mathrm{p}<0.05, \mathrm{p}<0.01$, single tail test (the same below). 
Table 2. Regression analysis results of network structure and technology distance on firm's cooperative innovation output.

\begin{tabular}{|c|c|c|c|c|c|}
\hline Variable & Model 1 & Model 2 & Model 3 & Model 4 & Model 5 \\
\hline \multirow[t]{2}{*}{ Firm's Scale } & $0.186^{* * *}$ & $0.088^{\star * *}$ & $0.082^{* * *}$ & $0.076^{* * *}$ & $-0.045^{\star *}$ \\
\hline & $(0.000)$ & $(0.002)$ & $(0.009)$ & $(0.009)$ & $(0.017)$ \\
\hline \multirow[t]{2}{*}{ Firm's Age } & -0.003 & -0.004 & 0.000 & 0.003 & 0.002 \\
\hline & $(0.672)$ & $(0.547)$ & $(0.967)$ & $(0.672)$ & $(0.730)$ \\
\hline \multirow[t]{2}{*}{ State-Owned Enterprise } & $-0.511^{* *}$ & -0.104 & -0.097 & -0.060 & 0.209 \\
\hline & $(0.044)$ & $(0.641)$ & $(0.677)$ & $(0.776)$ & $(0.316)$ \\
\hline \multirow[t]{2}{*}{ Foreign Enterprise } & $-0.609^{*}$ & -0.302 & -0.324 & -0.284 & -0.054 \\
\hline & $(0.093)$ & $(0.347)$ & $(0.327)$ & $(0.355)$ & $(0.859)$ \\
\hline \multirow[t]{2}{*}{ Joint Enterprise } & $-0.948^{\star *}$ & -0.571 & -0.472 & -0.418 & -0.313 \\
\hline & $(0.036)$ & $(0.157)$ & $(0.253)$ & $(0.278)$ & $(0.415)$ \\
\hline \multirow[t]{2}{*}{ Private Enterprise } & -0.136 & -0.026 & 0.081 & -0.083 & -0.081 \\
\hline & $(0.617)$ & $(0.912)$ & $(0.742)$ & $(0.712)$ & $(0.719)$ \\
\hline \multirow[t]{2}{*}{ Network Centrality } & & $0.303^{\star * *}$ & $0.788^{\star * *}$ & $0.173^{\star * *}$ & $0.595^{* * *}$ \\
\hline & & $(0.000)$ & $(0.000)$ & $(0.000)$ & $(0.000)$ \\
\hline \multirow[t]{2}{*}{ Structural Holes } & & & $1.671^{\star * *}$ & $0.787^{\star * \star}$ & $0.165^{\star *}$ \\
\hline & & & $(0.000)$ & $(0.001)$ & $(0.041)$ \\
\hline \multirow[t]{2}{*}{ Technical Distance } & & & & $0.603^{\star * *}$ & $0.306^{\star * *}$ \\
\hline & & & & $(0.000)$ & $(0.002)$ \\
\hline \multirow[t]{2}{*}{ Technical Distance $\wedge 2$} & & & & $-0.872^{\star * \star}$ & 0.075 \\
\hline & & & & $(0.001)$ & $(0.310)$ \\
\hline Network Centrality $\times$ & & & & & $-0.304^{\star *}$ \\
\hline Technical Distance & & & & & $(0.038)$ \\
\hline Structural Holes $\times$ & & & & & $0.347^{* * *}$ \\
\hline Technical Distance & & & & & $(0.000)$ \\
\hline \multirow[t]{2}{*}{ Constant term } & -0.094 & 0.109 & 0.208 & 0.174 & $1.323^{* * *}$ \\
\hline & $(0.828)$ & $(0.771)$ & $(0.605)$ & $(0.588)$ & $(0.000)$ \\
\hline alpha & $0.727^{\star * *}$ & $0.462^{\star * *}$ & $0.504^{\star * *}$ & $0.365^{\star * *}$ & $0.349^{* * *}$ \\
\hline Log likelihood & -464.463 & -427.418 & -437.586 & -414.341 & -411.255 \\
\hline LR Chi-square & $54.17^{\star \star \star}$ & $138.26^{* * *}$ & $107.92^{\star * *}$ & $154.41^{* * *}$ & $160.5^{\star * *}$ \\
\hline Pseudo $\mathrm{R}^{2}$ & 0.0551 & 0.1305 & 0.1098 & 0.1571 & 0.1643 \\
\hline
\end{tabular}

The Pseudo $\mathrm{R}^{2}$ of model 5 was 0.1643 , which was not only higher than that of model 4 Pseudo $\mathrm{R}^{2}$ (0.1571), but also the highest among all models, indicating that the technology distance had significant moderating effect, so model 5 had the best explanatory level for dependent variables. Compared with the results of model 5 and model 4 shows that the network technology center distance is significant at the $5 \%$ level, and the regression coefficient is -0.304 , that technology distance plays a negative moderating effect on the network centrality influence 
on the performance of technical innovation cooperation in technology when the distance is, the impact of network centrality on cooperation the smaller the performance of technology innovation. The interaction effect between structure holes and technology distance is significant at the $1 \%$ level, the regression coefficient was 0.347 , indicating the technology distance plays a regulatory role in the impact of the structural holes on the cooperative technological innovation performance. When the technology distance is bigger, the effect of structural holes on cooperative innovation performance is more. Hypothesis $3 \mathrm{a}$ and hypothesis 3B were validated by regression analysis.

\section{Discussion and Implications}

\subsection{Discussion}

According to the collation and analysis of the empirical analysis results, this study draws the following conclusions:

1) Both the location of the network center and the location of the structural holes have a positive impact on the firms' cooperative innovation output. When the firm is in the central position of the network, it is easier to search the resources in the network and obtain more valuable information, in order to identify the most appropriate partners with complementary skills, so as to promote cooperative innovation. The firm occupies the structural hole position, means that the firm plays the role of a bridge, because it can control all kinds of key information and key resources, you can quickly learn new market opportunities and potential risk, improve the success rate of cooperative innovation activities, promote cooperation and innovation output.

2) There is an inverted $U$ relationship between technological distance and cooperative technological innovation performance. The distance by a factor of two absorption ability and information value influence the cooperative innovation performance of firms, the greater the technology distance firms to provide more abundant information flow, the higher the value, is conducive to cooperation and innovation activities, but firms effectively absorb knowledge and technology into production and technology innovation but the distance is negative correlation.

3) The interaction between technology distance and network centrality has a negative impact on the technological innovation performance of firm's cooperation. For firms with high technology distance, the positive impact of network centrality on cooperative technology innovation performance is relatively weak, while for firms with low technology distance, network centrality has a positive impact on cooperative technology innovation performance. This shows that when the firm's technology distance with other partners is large, rich information resources of firms through technological distance brought to replace the center position in the firm's cooperation in the network information resources, so as to reduce the effect of network centrality on cooperative innovation performance. And when the technical distance between firms is relatively small, it is 
necessary to obtain the information resource revenue through the central position of the dominant position in the network, so as to improve the performance of cooperative innovation.

4) The interaction between technology distance and structural holes has a positive impact on the technological innovation performance of firm's cooperation. When the technical differences between firms and their cooperative firms are relatively large, the positive influence of structural holes on cooperative technological innovation performance is strong, otherwise it is relatively weak. This shows that if the establishment of technical cooperation firms and technology is very close to the firm, even if the firm is on structure holes position, the network for the firm to provide novel information potential is very limited, and cannot effectively the network position advantage into technological innovation.

\subsection{Implications for Practice}

According to the conclusions of the empirical analysis, this study has some enlightenment for the management practice of domestic and foreign firms:

1) Taking advantage of the location of the network center and the location of the structure holes are beneficial to enhance the performance of cooperative technology innovation. Therefore, firms should consciously and actively expand the potential partners, and strive to maintain the existing cooperative firms, to build a wide range of cooperation between firms to enhance their own network, in the network center, and access to the network more innovative resources, enhance the ability of cooperative innovation.

At the same time, firms should actively establish cooperation relationship with different types of firms, try to act as the bridge of different cooperation groups, and absorb heterogeneous technology knowledge extensively, so as to occupy the structural holes position which is beneficial to cooperative innovation performance.

2) The technical distance between firms is too large or too small to help firms to cooperate in technological innovation performance, and there is an optimal technology distance to maximize the technological innovation performance of firms. Firms can adjust firm's development strategy and partner selection strategies according to their actual situation: when the firm is in mature stage, in a technical field has been at the leading level, has the strong ability of scientific research and technology knowledge absorptive capacity, firms can choose different technology firms establish a technology partnership, contact technical knowledge more in other areas, and actively expand the field of firm's technology, the required technical innovation search firm's external resources, the pursuit of more radical product innovation value, and promote the technological innovation performance of firms; when the firm is in the initial stage, the technical level of firms is still relatively low, the firm can establish technical cooperation and technology selection comparison of small firms, new technology and knowledge more to learn and absorb external firm, actively enhance the technical level of firms, and gradually enhance the competitiveness of firms in the market, and 
strive to catch up with the industry leader in the market.

3) The relationship between technology distance negatively regulating network centrality and cooperative technology innovation performance positively moderates the relationship between structural holes and cooperative technology innovation performance. When the firm is not in the network center, the firm acquired from the network information resources are limited, the firm can properly select firm's technology gap to establish technical cooperation, to make up for the firms in the network position advantage, actively acquire new knowledge in order to promote the technology on the development of the firm's cooperative network. When the firm is in the structure holes position of the cooperative network, firms can obtain more heterogeneous knowledge and communication and control of heterogeneous knowledge in the network, if the establishment of cooperative relationship between firms and the selection of technology is large, the value of information and control of income will be further enlarged. Therefore, this paper provides guidance for firms to build cooperative technology innovation network, select the location of firms in the network and how to select partners.

The shortcomings of this study are that it has only 189 nodes in its cooperative network. So the network is only enough for the perspective of the overall network construction the static network of firm's cooperative innovation. Therefore, future research can consider to construct a larger firm's collaboration network, and examine the impact of firm's network position in local network on firm's collaborative innovation, and can collect panel data for further dynamic test.

\section{Conflicts of Interest}

The authors declare no conflicts of interest regarding the publication of this paper.

\section{References}

[1] Koka, B.R. and Prescott, J.E. (2008) Designing Alliance Networks: The Influence of Network Position, Environmental Change, and Strategy on Firm Performance. Strategic Management Journal, 29, 639-661. https://doi.org/10.1002/smj.679

[2] Dougherty, D. and Hardy, C. (1996) Sustained Product Innovation in Large, Mature Organizations: Overcoming Innovation to Organization Problems. Academy of Management Journal, 39, 1120-1153.

[3] Brown, J.S. and Duguid, P. (1991) Organizational Learning and Communities-of-Practice: Toward a Unified View of Working, Learning, and Innovation. Organization Science, 2, 40-57. https://doi.org/10.1287/orsc.2.1.40

[4] Burt, R.S. (1992) Structural Holes: The Social Structure of Competition. Harvard University Press, Cambridge.

[5] Soda, G., Usai, A. and Zaheer, A. (2004) Network Memory: The Influence of Past and Current Networks on Performance. Academy of Management Journal, 47, 893-906. 
[6] Gilsing, V., Nooteboom, B., Vanhaverbeke, W., et al. (2008) Network Embeddedness and the Exploration of Novel Technologies: Technological Distance, Betweenness Centrality and Density. Research Policy, 37, 1717-1731.

https://doi.org/10.1016/j.respol.2008.08.010

[7] Freeman, L.C. (1979) Centrality in Social Networks: Conceptual Clarification. Social Networks, 1, 215-239. https://doi.org/10.1016/0378-8733(78)90021-7

[8] Ahuja, G. (2000) Collaboration Networks, Structural Holes and Innovation: A Longitudinal Study. Administrative Science Quarterly, 45, 425-455. https://doi.org/10.2307/2667105

[9] Jaffe, A.B. (1986) Technological Opportunity and Spillovers of R\&D: Evidence from Firms' Patents, Profits and Market Value. American Economic Review, 76, 985-1001.

[10] Bar, T. and Leiponen, A. (2012) A Measure of Technological Distance. Economics Letters, 116, 457-459. https://doi.org/10.1016/j.econlet.2012.04.030 